\title{
Strength And Durability Properties Of Steel Fiber Reinforced Self Compacting Concrete
}

\author{
Sumith Vangara ${ }^{1}$, S Siva Rama Krishna ${ }^{2}$, Venu Malagavelli ${ }^{3}$, K.Tarunkumar ${ }^{4}$, A. Jagadish \\ Babu $^{5}$ \\ ${ }^{1}$ Student, Institute of Aeronautical Engineering, Hyderabad, India. \\ ${ }^{2}$ Assistant Professor, Institute of Aeronautical Engineering, Hyderabad, India. \\ ${ }^{3}$ Professor, Institute of Aeronautical Engineering, Hyderabad, India. \\ ${ }^{45}$ Assistant Professor, Institute of Aeronautical Engineering, Hyderabad, India. \\ ${ }^{1}$ sumithvangara@gmail.com, ${ }^{2}$ 141sivaramakrishna@gmail.com, ${ }^{3}$ Venu.bits@ gmail.com, \\ ${ }^{4}$ Tarun127@gmail.com, ${ }^{5}$ Ajagadish700@ gmail.com
}

Article History: Received: 11 January 2021; Accepted: 27 February 2021; Published online: 5 April 2021

\begin{abstract}
In this present study the durability characteristics of Steel fiber reinforced Self compacting concrete (SFRSCC) is determined for M30 and M40 grade concrete mixes. Along with durability strength and sorptivity is carried out and comparison is made with Plane self-compacting concrete (SCC) by chemical resistances, Initial Surface Absorption Test (ISAT).

In the present study, the rational mix design procedure for self-compacting concrete is used. SCC mixes contains large quantity of powder (material whose parcel size is $0.125 \mathrm{~mm}$ ) to maintain the plastic yield of the properties of fresh concrete as per the general guidelines for design of SCC mixes given in the EFNARC (2005). The present project consists of two phases. In the first phase, SCC mixes for different grades are developed without steel fibers and with steel fibers. The mechanical properties like compressive strength of the different grades were studied. In the second phase, based on the experimental results, durability properties were studied with the using of specimens of size $100 \mathrm{~mm} \times 100 \mathrm{~mm} \times 100 \mathrm{~mm}$. Durability studies like Acid attack factors, AcidDurability factors, Sulphate attack factors, Sorptivity are studied for the Plain SCC and steel Fiber Reinforced SCC and a comparison is made.
\end{abstract}

Keywords: Self Compacting Concrete, Steel Fiber Reinforced, Strength, Durability, Sorpitivity.

\section{Introduction}

Self-compacting concrete (SCC) is the one in which the compaction of concrete is done under its own weight. Generally, in case of normal concrete mixes vibrations or compaction is main thing to make concrete specimens but in case of SCC these vibrations and compactions is not important. The mix proportion of SCC is different as compared with normal concrete mix. In this paper I was considered compressive strength for SCC along with this durability and sportivity also studied.

The strength of the concrete is main and important concept in concrete studies, this strength is depends upon various parameters like material properties and mix proportion the strength will increases or decreases depending upon these two parameters. In some times in the concrete cracks will observed due to many reasons these cracks also decrease the effect of strength values. The main concept of using fibers in concrete is to increase the strength and at the same time we can decrease the cracking effect also. There are different types of fibers are there which helps to decrease the cracking effect and to increase the strength like steel fibers, polypropylene fibers, polyester fibers, carbon fibers, micro synthetic fibers, natural fibers and cellulose fibers. Depending upon the applications we will use fibers in concrete to increase the strength values. In the present study I was selected steel fibers in M30, M40 grade concrete to study the comparison of strength, durability and sportivity values. The compressive strength is determined at the curing age of 7 days and 28 days with and without using fibers. The present study it was divided into two phases in phase I workability and compressive strength is determined, in phase II Durability and sportivity is determined with and without using steel fibers.

\section{Materials and methods}

The following are the materials which are used in the present project with specification.

\section{Cement}

Cement is the main binding material which is used in concrete mix. For the current study cement of OPC 53 Grade which is available in local market is used. The preliminary tests are conducted on cement by using IS: 4031-1988 and found to confirming to IS: 12269-1987. The cement sample is shown in below figure 1 


\section{Fine Aggregate}

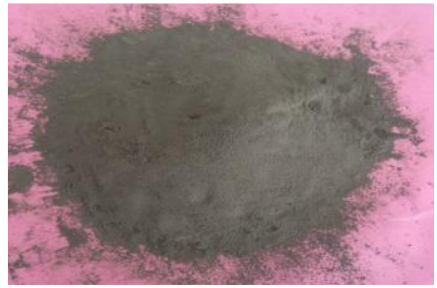

OPC 53 grade cement

Fine aggregates are the particles which are passing through $4.75 \mathrm{~mm}$ IS sieve. The river sand which is available in local market is used in this study the sample is shown in below figure 2 . The preliminary investigation of fine aggregates is conducted according to IS: 2386-1963.

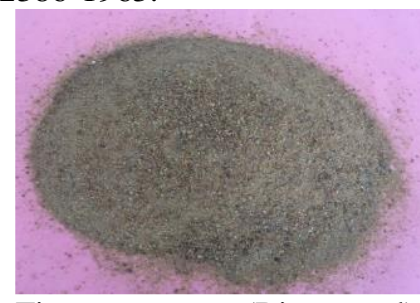

\section{Coarse aggregates}

Fine aggregates (River sand)

The coarse aggregates are the sample which are retained on the 4.75 is sieve. For this study I was taken sample which is passing through $12.5 \mathrm{~mm}$ sieve and retained on $10 \mathrm{~mm}$ sieve was taken the coarse aggregates preliminary tests was conducted according to IS 2386-1963 code which is shown in below figure 3 .

\section{Fly Ash}

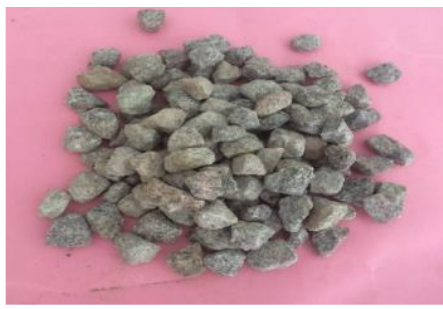

Fly ash is one of the most important by product which is used in construction industry. The fly ash sample is shown in below 4 . The physical and chemical properties of fly ash is determined by using IS: 3812-2003.

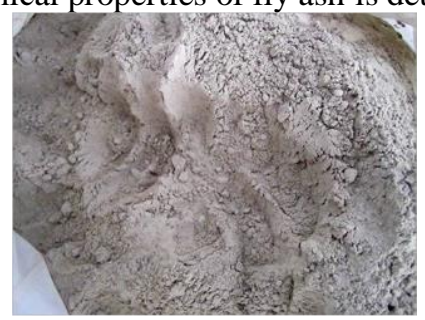

Fly ash

\section{Super Plasticizer}

Super Plasticizer with Sulphonated Naphthalene Formaldehyde (SNF) of Comp last SP430 DIS was confirming to IS: 9103-1999 used in this investigation which is shown in below figure 5.

\section{Viscosity Modifying Admixture (VMA)}

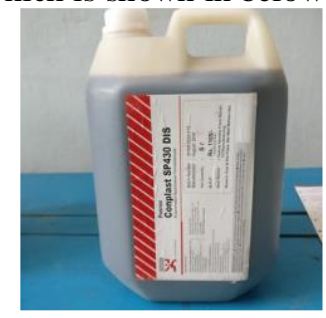

Super Plasticizer

Rooftop PLAST VMA2 is prepared to-utilize, fluid, natural, Viscosity Modifying Admixture (VMA) extraordinarily created for delivering concrete with improved consistency and controlled rheological 
properties.Rooftop PLAST VMA2 is utilized as a Viscosity altering specialist from a standard organization affirming to standard particulars was likewise utilized.

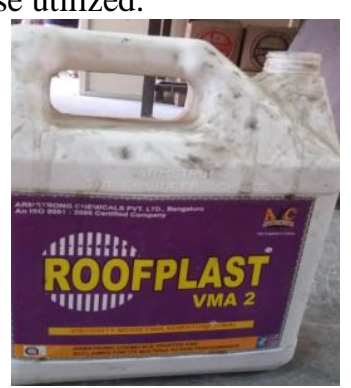

Viscosity Modifying Agent

\section{Water}

Portable water confirming to IS: 3025-1986 part $22 \& 23$ and IS: 456-2000 was used in the investigation.

\section{Steel Fibers}

Hooked end steel fibers of $0.4 \mathrm{~mm}$ diameter and Aspect ratio of 30- and 12-mm length were used.

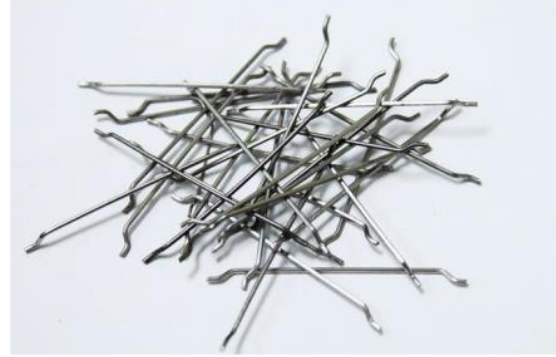

$$
\text { Steel Fibers }
$$

Mix Design and Trail Mix Proportions of Self Compacting Concrete

An SCC mixes of M30 and M40 were aimed and the initial mix proportions were obtained using the mix design methods.

\begin{tabular}{|l|l|l|l|l|l|l|l|l|}
\hline Grade & $\begin{array}{l}\text { Cement } \\
(\mathbf{K g})\end{array}$ & $\begin{array}{l}\text { Fine } \\
\text { Aggregate } \\
\mathbf{( K g )}\end{array}$ & $\begin{array}{l}\text { Coarse } \\
\text { Aggregat } \\
\mathbf{e}(\mathbf{K g})\end{array}$ & $\begin{array}{l}\text { Fly } \\
(\mathbf{K g})\end{array}$ & ash & $\begin{array}{l}\text { Water } \\
(\mathbf{L i t})\end{array}$ & Super Plasticizer & VMA \\
\hline 30 & 388 & 885 & 700 & 318 & 210 & 10.8 & $\mathbf{\%}$ & $(\mathbf{\%})$ \\
\hline 40 & 468 & 884 & 700 & 350 & 240 & 12.27 & 1.5 & 0.06 \\
\hline
\end{tabular}

\section{EXPERIMENTAL INVESTIGATION}

PHASE I: Development of plain SCC and investigations on its fresh and hardened properties.

\section{Mixing of ingredients}

The materials like cement, fine aggregates, coarse aggregates, fly ash, super Plasticizer, Viscosity Modifying Agent and steel fibers are mixed as per the mix proportion which is shown in table 1

\section{Workability of SCC}

After making the SCC mix the workability of SCC like Slump Flow Test and T50 cm Test, V-Funnel Test, LBox Test were determined for with and without using steel fibers cases.

\section{Casting of specimens}

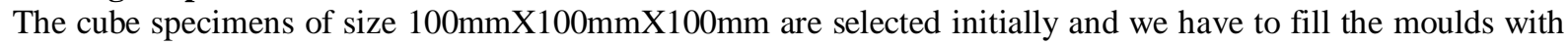
specified mix of SCC with specified trial to determine the compressive strength at 7 days, 28 days curing which is shown in below figures.

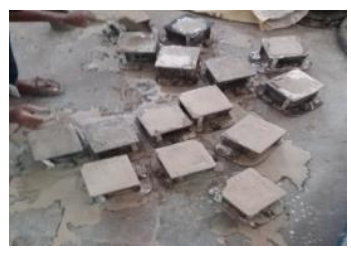

Casting of cubes of SCC 


\section{Curing of test specimens}

After casting cubes leave them for 24 hours at room temperature to make specimens to hard condition after then de mould the cubes from moulds and allow them to curing tank for 7 days and 28 days curing.

\section{Compressive strength of SCC}

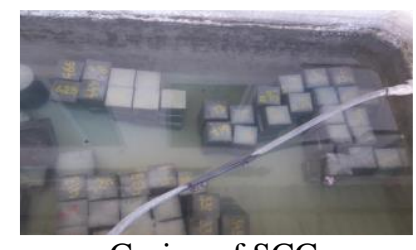

Curing of SCC

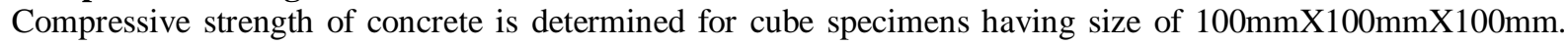
this test is carried out by using Compression Testing Machine (CTM) having its capacity of 200T. For the current study the compressive strength is determined for steel fiber reinforced concrete in M30 and M40 grades of concrete with the help of IS 516-1959 code Book.

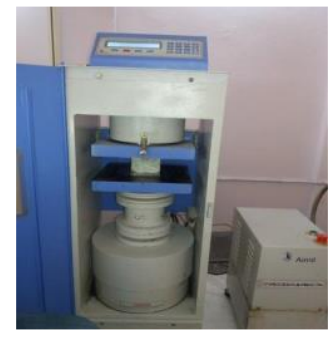

Compression testing machine (CTM)

PHASE II Study the durability properties of plain SCC and steel FIBER reinforced Self Compacting Concrete.

The durability of SCC is determined by curing the test samples in acid and sulphate solutions for required days of curing periods. The results like acid and sulphate strength loss and weight loss factors, acid durability loss factors for SCC and SFRSCC mixes.

Sorptivity is a file of dampness transport into unsaturated solid examples. Sorptivity has been perceived as a significant file of cement. sorptivity mirrors the manner in which water and different damaging specialists will infiltrate into the solid and it speaks to a particularly decent measure it is dictated by utilizing factor consumed water per unit region against time.

\section{Results and discussion}

\section{Fresh Concrete properties (Workability of SCC)}

\begin{tabular}{|l|l|l|l|l|l|}
\hline \multirow{4}{*}{ Grade } & \multicolumn{2}{|l|}{ Fresh properties } & \multirow{2}{*}{ Remarks } & \multirow{2}{*}{ Designation } \\
\cline { 2 - 6 } & $\begin{array}{l}\text { Slump flow } \\
\text { T50 cm } \\
\text { Test Sec }\end{array}$ & $\begin{array}{l}\text { V- Funnel } \\
\text { Test Sec }\end{array}$ & $\begin{array}{l}\text { L- Box } \\
\text { Test H2/H1 }\end{array}$ & Remarks \\
\hline \multirow{3}{*}{30} & 2.23 & 6.17 & 0.73 & RNS & SCCP-1 \\
\cline { 2 - 6 } & 2.78 & 8.23 & 0.78 & RNS & SCCP-2 \\
\cline { 2 - 6 } & 2.70 & 6.76 & 0.94 & RS & SCCP \\
\cline { 2 - 6 } 40 & 3.20 & 7.58 & 0.915 & RS & SFRSCC \\
\hline \multirow{3}{*}{} & 3.59 & 7.53 & 0.956 & RS & SCCP \\
\cline { 2 - 5 } & 3.98 & 7.98 & 0.88 & RS & SFRSCC \\
\hline
\end{tabular}

RNS - Result Not Satisfied in Fresh State RS - Result Satisfied in Fresh State 


\section{Compressive strength of concrete}

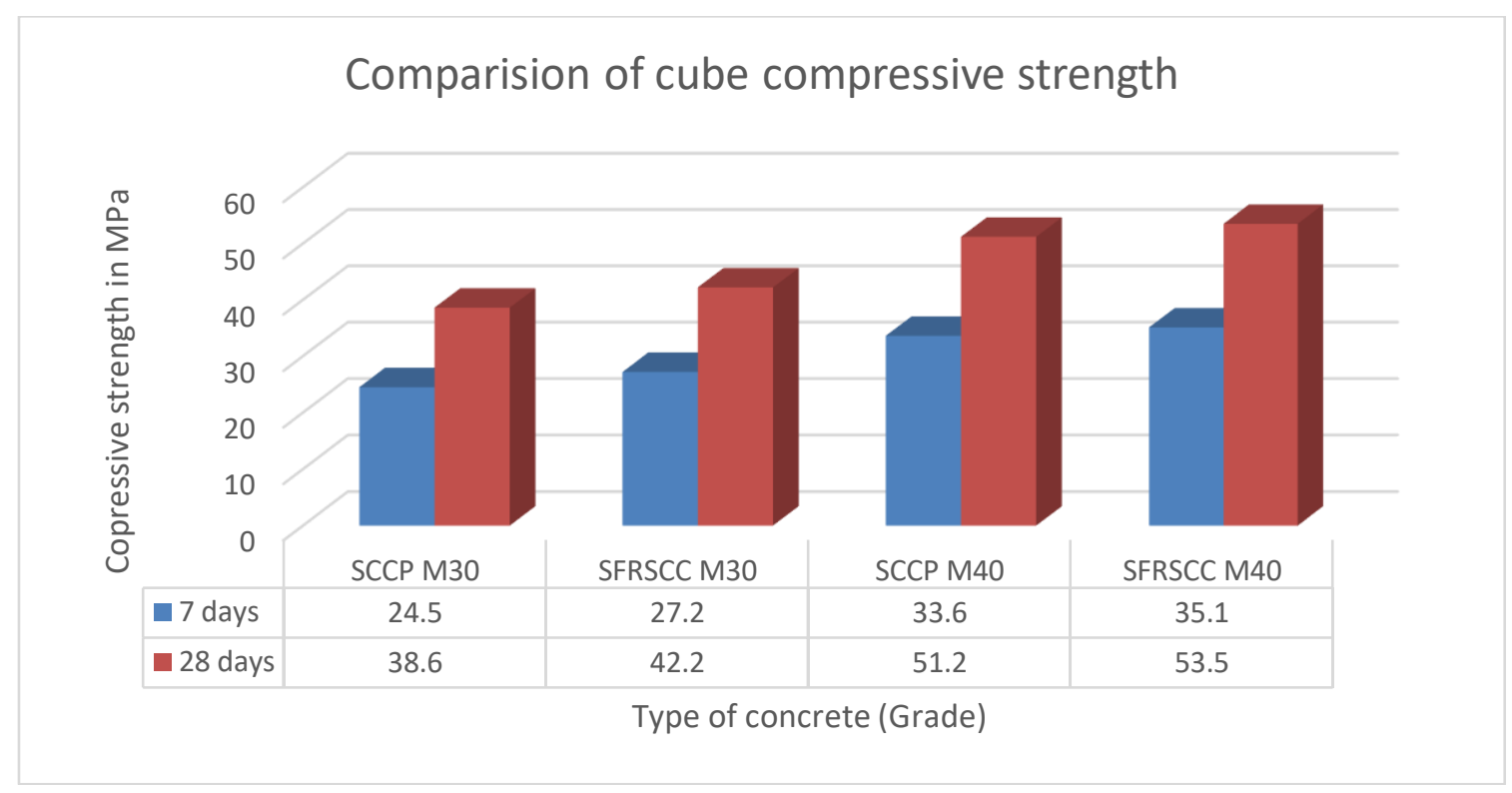

The cube compressive strength of the concrete is measures in MPa at 7 days and 28 days curing for M30 and M40 grade concrete mixtures the results are shown in above graph from the graph it was observed that for M30 grade and M40 grade mixes the value of compressive strength is higher for concrete mix by using steel fibers than normal mix due to proper mixture which obtained for steel fibers mix the compressive value obtained higher value.

\section{DURABILITY OFSCCANDSFRSCC}

\section{Comparision of Acid strength loss factors for 28 days curing}

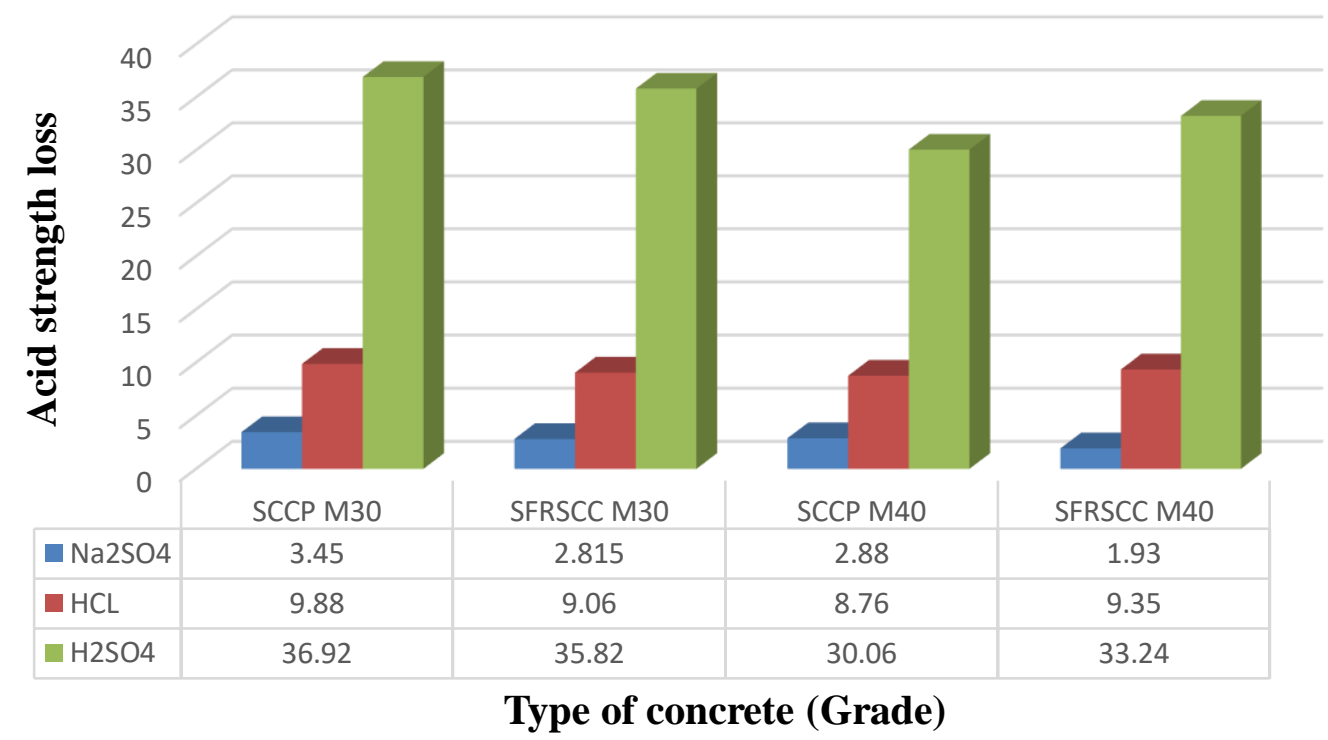

The acid strength loss factors are measures for M30 and M40 grade mixtures by using chemicals $\mathrm{Na}_{2} \mathrm{SO}_{4}, \mathrm{HCL}$ and $\mathrm{H}_{2} \mathrm{SO}_{4}$ at 28 days curing the values are shown in above graph from there it was obtained that the steel loss factor has higher values for $\mathrm{H}_{2} \mathrm{SO}_{4}$ solution curing than $\mathrm{HCL}$ and $\mathrm{Na}_{2} \mathrm{SO}_{4}$. When concrete specimen is exposed to $\mathrm{H}_{2} \mathrm{SO}_{4}$ curing the chemical reaction between solution and concrete is higher due to that reason the results obtained higher for $\mathrm{H}_{2} \mathrm{SO}_{4}$ case. 


\section{Comparision of Acid strength loss factors for 56 days curing}

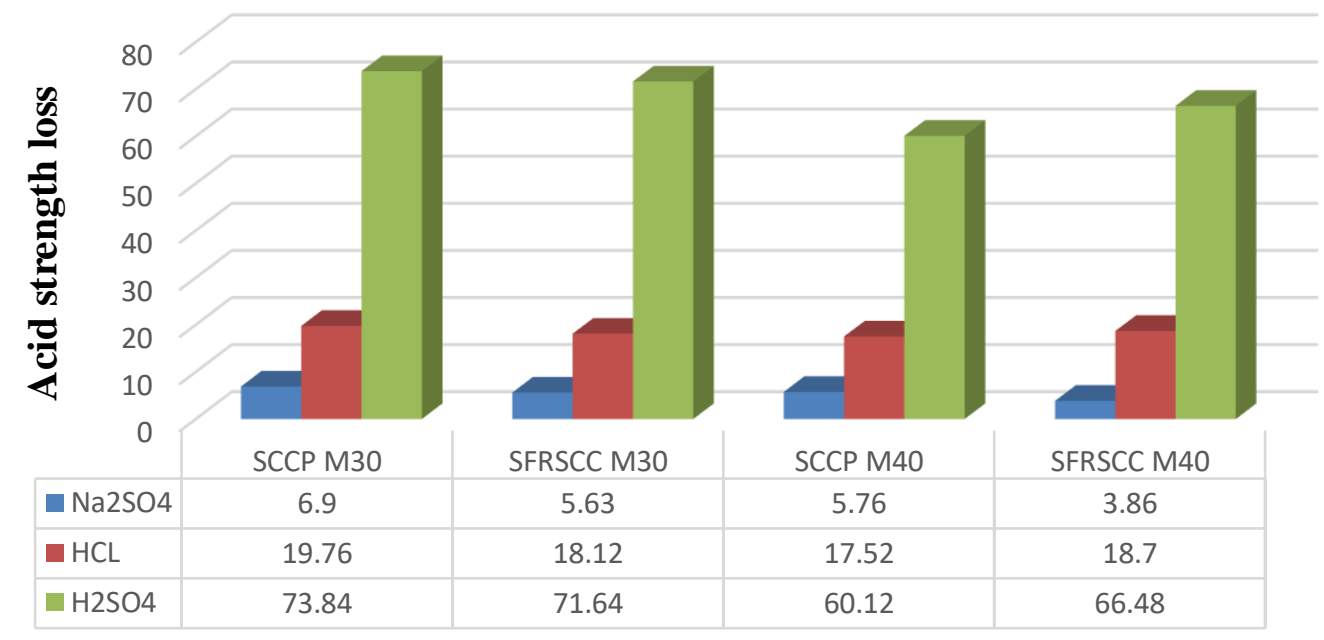

Type of concrete (Grade)

The acid strength loss factor for 56 days curing is shown in above graph here also obtained similar results like 28 days curing case $\mathrm{H}_{2} \mathrm{SO}_{4}$ curing the chemical reaction between solution and concrete is higher due to that reason the results obtained higher for $\mathrm{H}_{2} \mathrm{SO}_{4}$ case for $\mathrm{M} 30$ and $\mathrm{M} 40$ grade concrete mix.

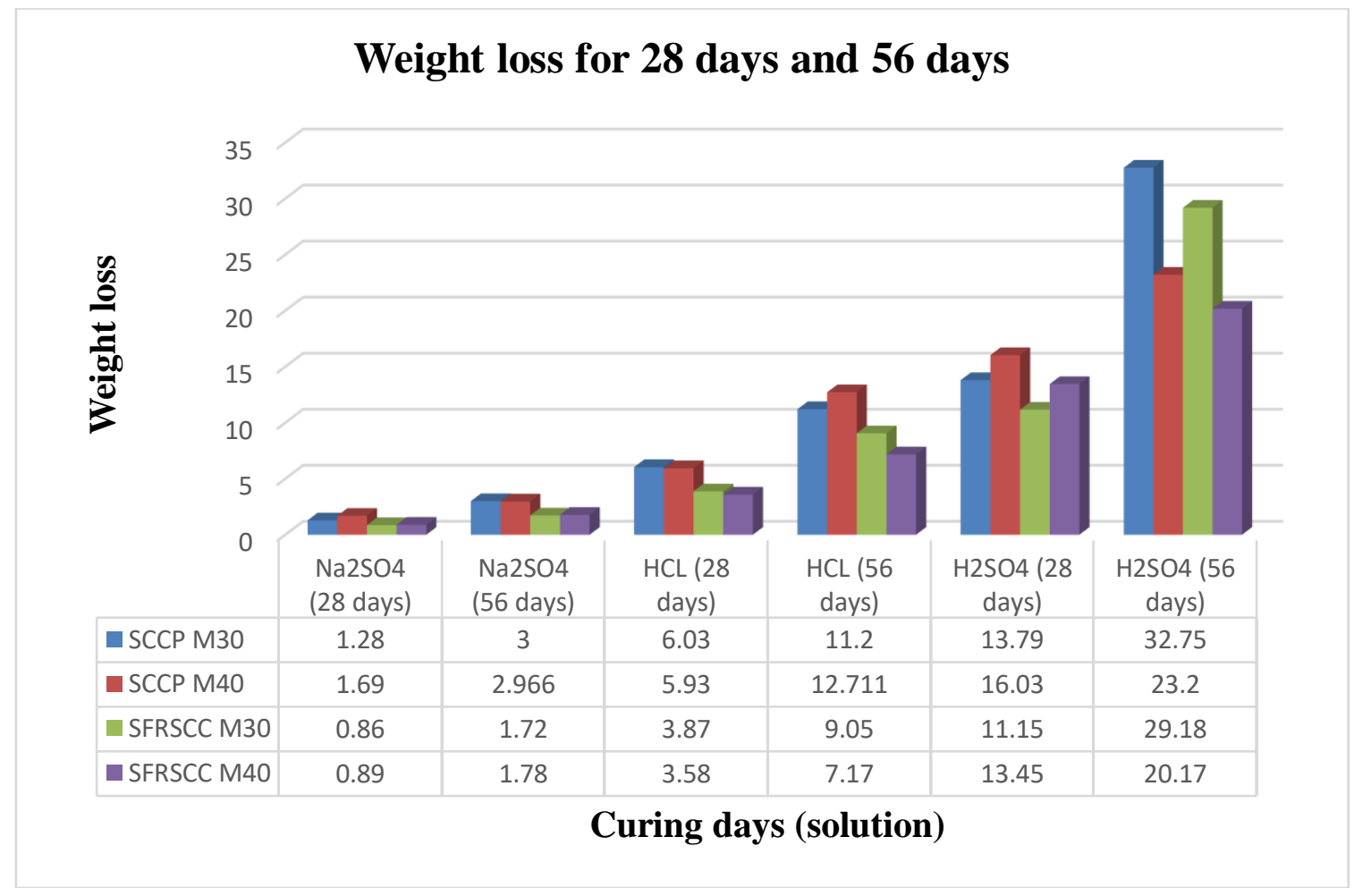

The percentage weight loss for 28 days and 56 days for M30, M40 grade is shown in above graph from there it was obtained that the weight loss has higher values for $\mathrm{H}_{2} \mathrm{SO}_{4}$ solution then HCL and $\mathrm{Na}_{2} \mathrm{SO}_{4}$. 


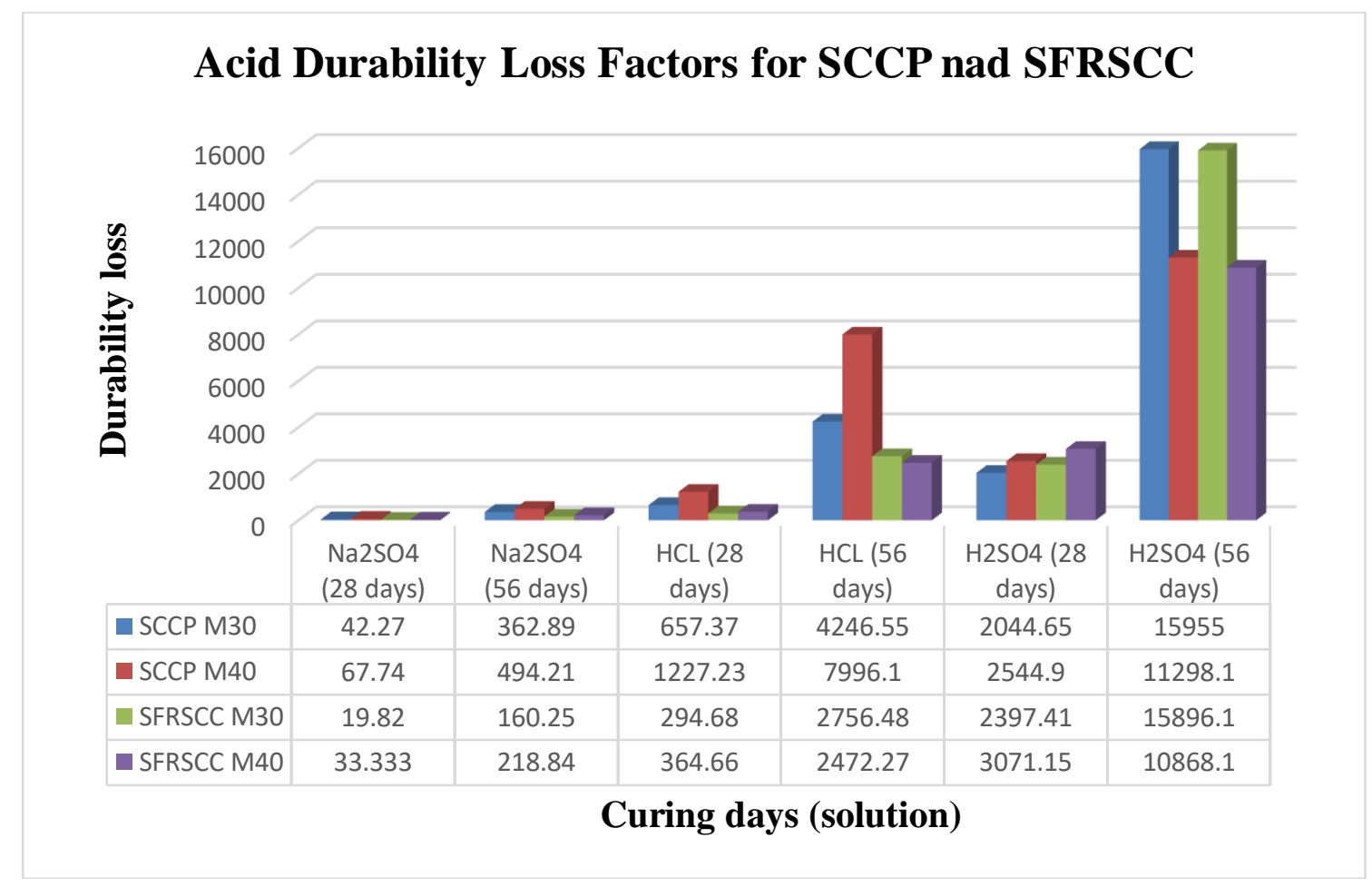

Acid durability loss factor for SCCP and SFRSCC for 28 days and 56 days is shown in above graph the acid durability factor is also has higher values for $\mathrm{H}_{2} \mathrm{SO}_{4}$ solution curing.

Sorptivity Study on SCC and SFRSCC

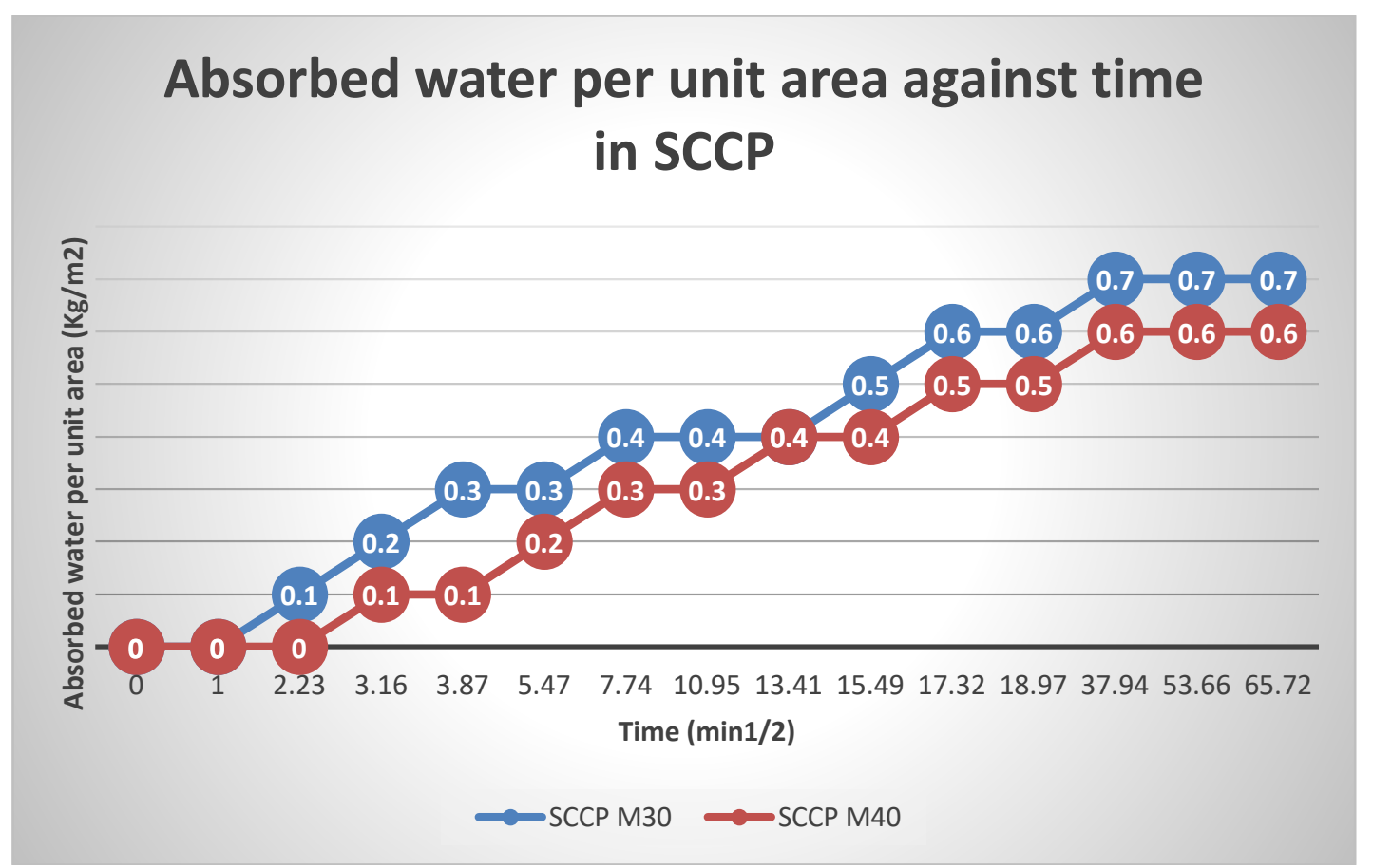

The results of absorbed water per unit area against time for SCCP is shown in above graph the value of absorbed water increases with increasing the time for M30 and M40 grade concrete mix 


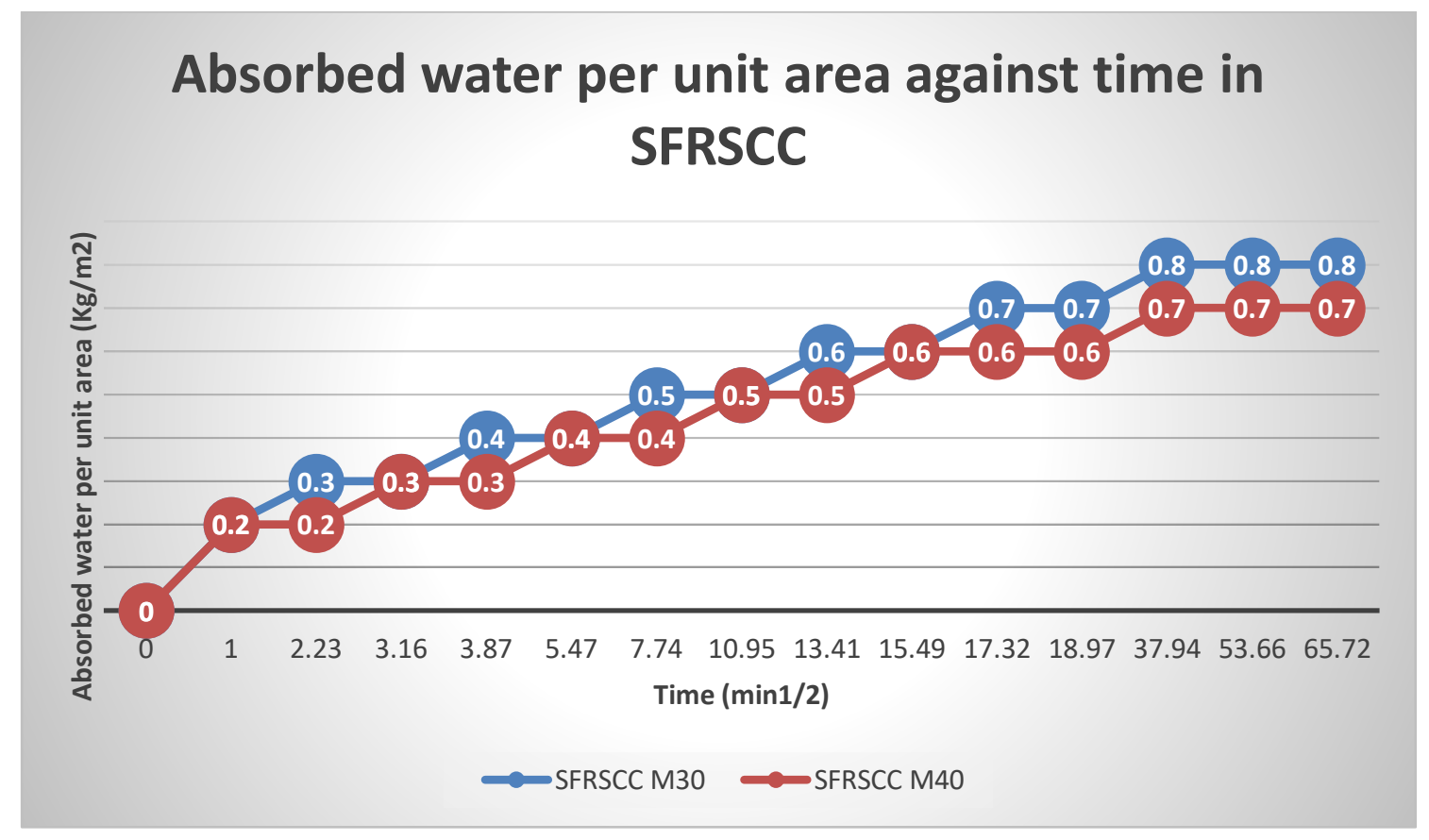

The results of absorbed water per unit area against time for SFRSCC is shown in above graph the value of absorbed water increases with increasing the time for M30 and M40 grade concrete mix.

\section{Conclusions}

- $\quad$ Fiber reinforced self-compacting concrete is made with steel fiber to improve its strength properties. The aspect ratio of the fiber is important factor in this study as per results $12 \mathrm{~mm}$ fibers with 30 aspect ratio is giving better results than other cases.

- $\quad$ For M30 grade and M40 grade concrete the value of compressive strength is observed as $2 \%$ to $10 \%$ more than plain concrete mix. With increase of FIBER dosage, the workability decreases. This problem of workability and flow proprieties of concrete can be overcome by adding super plasticizers and VMA. With the increase in the grade of concrete the sorptivity of Steel FIBER Reinforced SCC was found to be lower similarly in plain SCC also.

- In SFRSCC the amount of water absorption per unit area decreases with increase in the grade of concrete. The percentage loss of strength and percentage loss of weight factors in durability is less for SFRSCC mix than SCC in case of M30 and M40 grade concrete.

- WLF is less in Na2SO4 when compared to HCL and H2SO4. SFRSCC has shown 10\%-13\% more resistance to weight loss when it is immersed in $\mathrm{H} 2 \mathrm{SO} 4,15 \%-20 \%$ more resistance in $\mathrm{HCl}, 16 \%-20 \%$ more resistance in $\mathrm{Na} 2 \mathrm{SO} 4$ when compared to plain SCC.

- $\quad$ Acid weight loss factor is found to be decreases with increases in the grade of concrete. The loss of dimension stability is more in $\mathrm{H} 2 \mathrm{SO} 4$ when compared with $\mathrm{HCl}$ and $\mathrm{Na} 2 \mathrm{SO} 4$. SFRSCC has shown 1\%-3\% more resistance to dimension stability when immersed in $\mathrm{H} 2 \mathrm{SO} 4,5 \%-7 \%$ more resistance in $\mathrm{HCl}$ and $\mathrm{Na} 2 \mathrm{SO} 4$ when compared to plain SCC.

- The loss of dimension stability is found to be decreases with increase in grade of concrete. Acid strength loss percentage is more in $\mathrm{H} 2 \mathrm{SO} 4$ when compared with $\mathrm{HCl}$ and $\mathrm{Na} 2 \mathrm{SO} 4$.

- $\quad$ SFRSCC has shown 5\% more resistance to strength loss when immersed in $\mathrm{H} 2 \mathrm{SO} 4,9 \%$ more resistance in $\mathrm{HCl}$ and $\mathrm{Na} 2 \mathrm{SO} 4$ when compared to plain SCC. Acid strength loss percentage is found to be decreases with increases in grade of concrete.

- $\quad$ Acid durability loss factor decreases with increases in grade of concrete. When compared to the plain SCC, the SFRSCC was found to be more durable against both acids and sulphate.

\section{References}

1. Borsoi. A, Collepardi. M, Collepardi. S, Croce. E.N., Passuelo. A "Influence of Viscosity Modifying Admixture on the Composition of SCC" Supplementary volume of Eighth CANMET/ACI International Conference on Superplasticizers and other Chemical Admixtures in Concrete, October 29-November 1, 2006, Sorrento, Italy pp253-261. 
2. Chandrasekhar M, Seshagiri Rao M V, JanardhanaMaganti "Structural Behaviors Of Glass Fiber Reinforced Self Compacting Concrete Wall Panels" BEFIB2012-Fiber reinforced concrete, 20120.

3. Deng Min and Feng Naiqui, "The Influence of SP and Superfine Mineral Powder on the Flexibility, Strength and Durability of HPC". Cement and Concrete Research. 2000, Vol.31, pp703-706.

4. Giri Prasad. G, Seshagiri Rao M.V. and Rama Rao G.V. "Computation of Stress-Strain behavior of SelfCompacting Concrete in Higher Grade" International Journal of Scientific Computing, Vol.3, No.2 JulyDecember 2009 pp193-197.

5. K. Rajesh Kumar, N. Mahendran "Experimental Studies on Strength, Durability And behavior Of Beam Using S.C.C. With E-Glass Fiber Strands" International Journal of Engineering Research \& Technology (IJERT) Vol. 2 Issue 4, April - 2013.

6. Lachemi M and Hossain K. M. A. "Self-Consolidating Concrete incorporating New Viscosity Modifying Admixtures" Cement \& Concrete Research 34(2004), pp185-193.

7. Mallesh M, Shwetha G C, Reena K, Madhukaran "Experimental Studies on M30 Grade Self Compacting Concrete" International Journal of Science, Engineering and Technology Research (IJSETR), Volume 4, Issue 9, September 2015.

8. Nan Su, Kung-Chung Hsu, His-Wen Chai "A Simple Mix Design Method for Self-Compacting Concrete" Journal of Cement and Concrete Research 31(2001) pp 1799-1807.

9. Nishant Singh, Aditya R, Sri Rama Chand M and Rathish Kumar P "Strength and Durability Properties of Eco-SCC Using Recycled Aggregate from Building Demolished Waste (BDW)" Journal of Civil Engineering and Environmental Technology p-ISSN: 2349-8404; e-ISSN: 2349-879X; Volume 3, Issue 5; April-June, 2016, pp. 410415.

10. S.Siva Rama Krishna, VenuMalagavelli, V.S. Vani, "Effect of heat on mechanical properties of ternary blended recycled aggregate self-compacted concrete",Materials Today: Proceedings,Volume 38, Part 5,2021,Pages 3345-3350,ISSN 2214-7853,

11. Krishna, S. Siva Rama, V. S. Vani and ShaikKhaderValiBaba "Studies On Mechanical Properties Of Ternary Blended Self Compacting Concrete Using Different Percentages Of Recycled Aggregate" International Journal of Civil Engineering and Technology (IJCIET) Volume 9, Issue 11, November 2018, pp. 1672-1680, 